\title{
Supply Chain Risk Classification Schemes: A Literature Review
}

\author{
Manoj Hudnurkar \\ Symbiosis Centre for Management and Human Resource Development, \\ Plot No. 15, Phase-I, Rajiv Gandhi Infotech Park, Hinjewadi, Pune 411057, India \\ Email: manoj_hudnurkar@scmhrd.edu \\ Sujeet Deshpande \\ Symbiosis Centre for Management and Human Resource Development, \\ Plot No. 15, Phase-I, Rajiv Gandhi Infotech Park, Hinjewadi, Pune 411057, India \\ Email: sujeet_deshpande@scmhrd.edu (Corresponding Author) \\ Urvashi Rathod \\ Symbiosis Centre for Information Technology, \\ Plot No. 15, Phase-I, Rajiv Gandhi InfoTech Park, Hinjewadi, Pune 411057, India \\ Email: urvashi@scit.edu \\ Suresh K. Jakhar \\ Indian Institute of Management Lucknow, \\ Prabandh Nagar, IIM Road, Lucknow - 226013, India \\ Email: skj@iiml.ac.in
}

\begin{abstract}
The objectives of this paper are to review journal articles published between 2003 and 2015 related to supply chain risk sources, with a view to list and define supply chain risk sources identified by various researchers and critique the various supply chain risk classification schemes. For the purpose of this literature review, we adopted the methodology of a content analysis based literature review. Towards this end a conceptual risk classification framework was defined and supply chain risks identified by various researchers mapped into it. An analysis of the surveyed literature revealed the various supply chain risk sources and associated risks identified by the researchers. It is seen that while supply chain risk classification has been done by several researchers, it is not the main focus area of research for a majority of researchers but appears supplementary to other research goals. While the various supply chain risk classification schemes reviewed have sufficient breadth or depth to effectively address the diverse variety of supply chain risks, some important risk sources like product characteristics and returns processing have scope for further research. A new, comprehensive conceptual risk classification framework has been defined for the literature review. The review takes into account the current thinking on concept of risk and supply chain risks.
\end{abstract}

Keywords: supply chain risk, supply chain risk sources, supply chain risk classification

\section{INTRODUCTION}

Increasing complexity of products and Services has contributed to increase in outsourcing as firms no longer have the necessary expertise to make the products or provide services by themselves. Outsourcing often leads to offshore outsourcing or "offshoring" as organizations seek "best in class" vendors globally. Outsourcing coupled with increasing transnational movement of Capital, information, goods, labor and services has resulted in Supply chains becoming global, increasingly more complex and vulnerable to disruption risks (Harland, et al., 2003). There is also now a growing awareness about various risks and vulnerabilities that products face as they move along the various stages of the supply chain from design, procurement, manufacture, transportation, distribution and final sale to the consumer (Maruchek, et al., 2011).

Instances of disruptions to Supply Chains as a consequence of Risk Events abound in literature. In 2000, due to a fire at a Sub-Supplier facility in Albuquerque, New Mexico (USA), Ericsson suffered a major loss of US\$ 400 million. This loss was attributed to the gaps in supply of radio-frequency chips from the supplier facility (Norman \& Jansson, 2004). UPF-Thompson, the sole chassis supplier for Land Rover's bestselling SUV model, the Discovery went bankrupt in 2001. This brought Land Rover on the verge of shutting down its assembly lines for the Discovery model (Christopher \& Peck, 2004).The 6.8 magnitude earthquake which occurred in Japan in 2011 caused severe damage to production facilities of Riken Corp., a supplier of automobile components to Toyota. As a result of carrying limited inventories of Riken supplied components and its strategy of having close relationships with a limited number of suppliers, Toyota was forced to shut down all 12 of its domestic assembly plants, delaying production of 
approximately 55000 vehicles (Pettit, 2008). Prior to catastrophic flooding in 2011, Thailand accounted for $43 \%$ of world's computer hard disk drive production. Western Digital Corporation which produced one third of the world's hard disk drives, lost $45 \%$ of its shipments when their factory in Bang Pa-In industrial estate, Ayutthaya was inundated during the floods causing a loss of US\$ 199 million (Haraguchi \& Lall, 2013)(BBC News, 2012).Based on a worldwide survey of 537 respondents drawn from 14 industry sectors across 67 countries, (Alcantara \& Riglietti, 2015), have pointed out that $74 \%$ of survey respondents have experienced at least 1 instance of supply chain disruption in 2015.

In order to control and mitigate the consequences of supply chain disruptions and to reduce vulnerability of a supply chain to risks, Supply Chain Risk Management (SCRM) is assuming increasing importance as a discipline and the body of research in the field of SCRM is growing at a rapid pace.

In spite of supply chain risk being so commonplace and its impacts so evident, no universally accepted classification of supply chain risks currently exists (Rangel, et al., 2014) and (Sodhi, et al., 2012).According to (Sodhi, et al., 2012), this is due to a lack of common vocabulary of risk including supply chain risk across organizations in a supply chain.

The intent of this paper is to review the literature on supply chain risk management using content analysis based literature review methodology proposed by (Seuring \& Gold, 2012), with a view to list and define the supply chain risk sources identified by various researchers, critique the various approaches used for classification of supply chain risks and identify directions for further research into supply chain risk sources and supply chain risk classification schemes.

The literature reviewed comprised of peer reviewed journal articles in English published in international journals between 2003 and 2015, which proposed new classification scheme for supply chain risks or defined new supply chain risk sources. The year 2003 was chosen as a starting point for the study, as it was a year in which there was a surge in published research papers on supply chain risk management (SCRM)(Ghadge, et al., 2012). This is attributed partly to supply chain disruptions experienced as an aftermath of $9 / 11$ terrorist attacks and the resulting surge of interest in supply chain risk management (Chopra \& Sodhi, 2004). According to (Ghadge, et al., 2012), although 2001 was the year in which 9/11 attacks took place, the research on SCRM which started in 2001 resulted in published research papers in 2003 due to the publishing timelines involved.

The remainder of the paper is organized as follows section 2 defines the concepts of risk, supply chain risk and SCRM against the backdrop of supply chain management. It also examines the need and importance of having a universally accepted classification scheme for supply chain risks. Section 3 provides an overview of the research methodology. Section 4 presents the results of the literature survey. In section 5 we discuss our results, while in section 6 , we identify research gaps and directions for future research and conclude the paper.

\section{LITERATURE REVIEW}

\subsection{Supply Chain Management}

According to (Sodhi \& Tang, 2012), a supply chain is an interconnected network of organizations which includes suppliers, manufacturers, logistics providers, wholesalers, distributors and retailers that aims to produce and deliver products or services to the end customers. Supply Chain Management is the management of material, information and financial flows across the supply chain. It involves coordination between and control of various supply chain functions such as marketing, sales, product R\&D, procurement, production, logistics, information technology, and finance within the supply chain.

The Supply Chain Council (SCC) has standardized supply chain management processes in their SCOR-model (Supply Chain Council, 2010). The SCOR-model describes business activities associated with all phases of satisfying a customer's demands. The scope of the model spans from Suppliers' supplier to Customers' customer. Based on (Supply Chain Council, 2010) and (Sürie \& Wagner, 2005), supply chain management processes standardized by SCORmodel are - Plan, Source, Make, Deliver and Return. It is assumed that all organizations in the supply chain implement these management processes. Using the SCOR model it becomes possible to compare, analyze and evaluate not only supply chains of two companies but supply chains across different sectors of the industry.

Supply Chain Management is also tasked with monitoring, controlling and delivering Supply Chain Performance in accordance with Operational and Strategic performance metrics and continuous improvements in supply chain performance. Operational Performance metrics include the following:

1. Time related metrics such as product development cycle time, production lead time, delivery and replenishment lead times, cash-to-cash cycle

2. Cost related metrics such as product development cost, material, labor and production costs, inventory cost, shipping and handling costs

3. Customer satisfaction related measures such as product availability, product and service quality, after sales support and total lifecycle costs

Strategic performance metrics include metrics such as Return on Assets (ROA), profit, market share, revenue growth, and share price performance (Sodhi \& Tang, 2012).

Supply Chains are typically designed and managed to deliver, one or more outcomes as per Customer needs. (Melynk, et al., 2010), have recommended the following possible outcomes for a supply chain.

1. Cost - Reduce product costs, ensure timely, reliable delivery and quality

2. Responsiveness - Respond to changes in demand (volume, mix and location) quickly and at a reasonable cost.

3. Security - Ensure that the product flow through the supply chain is protected from disruption due to external threats. Ensure product integrity and consistency.

4. Sustainability - operate supply chain to ensure minimal and controlled resource impact now and in future. Implement and maintain a "Cradle-to-Cradle" perspective. "Cradle-to-Cradle" perspective seeks to 
design products such that they can be endlessly recycled so that waste is reduced to zero, natural resources are not depleted and environment is not polluted. This is in contrast with the "Cradle-to-Grave" approach.

5. Resilience - Develop a supply chain risk management system to react quickly and cost effectively to supply chain risks and disruptions.

6. Innovation - develop and provide new products meeting customer needs. Provide new ways of producing, delivering and distributing products.

\subsection{Concept of Risk}

Common dictionary definition of the term "Risk" is "the possibility that something unpleasant or unwelcome will happen" (Oxford Dictionaries, 2015). However, there is no consensus on how to define risk (Aven, 2012). According to (Aven, 2008), risk is related to future events whose occurrence is uncertain and their consequences (outcomes) which can have a range of possible values. Thus there is uncertainty associated with both events and their consequences. The likelihood of occurrence of events and that of resulting consequences can be expressed by means of Probabilities calculated on the basis of our prior knowledge of events and consequences. However, in many cases, Probabilities are not good measures of Uncertainty. In this formulation of risk, both positive and negative consequences are permitted. In practice however, the term risk is usually associated with undesirable or negative consequences. Based on the nature of consequences; risk is typically defined as follows:

1. Discrete Consequences: Here risk is associated with a discrete failure event. In this case the risk is defined as:

$$
\text { Risk }=P_{E} \times C_{E}
$$

Where $P_{E}$ is the probability of failure event and $C_{E}$ is the business impact or severity of the event (Heckmann, et al., 2015).

This definition of Risk is in line with the probabilistic risk assessment used to predict probability of safety failures of complex technological systems. It excludes unexpected events and assumes availability of historical data to calculate probabilities of failure events (Renn, 2008).

However, this approach to risk analysis is not without its drawbacks. First, what constitutes an undesirable business impact depends on the values and preferences of the people evaluating it. Second, the average probabilities may not capture the unique interaction between human actions and their consequences. Third, this definition does not capture the increase in actual risk due to failure of organizational processes in place for managing risks or from managerial risk taking. Fourth, the numerical combination of magnitude of potential losses and their probabilities of occurrence means that high impact/low probability events and low impact /high probability events with the same expected values, assume the same importance. However, people show distinct preference for allocating scarce risk management resources to low impact /high probability events and prioritize them over high impact /low probability events (Renn, 2008). According to (Simchi-Levi, et al,, 2015), low probability /high impact events are hard to predict and difficult to manage due to lack of historical data which can be used for estimating event probability and quantifying the risk. As a result, many firms do not adequately prepare for such events leaving them exposed to risk.

Another line of criticism of the probabilistic risk assessment approach is pointed out by (Aven, 2012). According to him, where probabilities are measured based on subjective assessment, the numbers assigned to probabilities do not reflect the amount of knowledge supporting the assessment. Two situations with the same subjective probability assignment could have vastly different knowledge bases supporting the assessment. In cases, where probabilities are calculated as frequency of occurrence, we need to have a stable, infinite population of similar events which serves as the basis for calculating the probability. In the case of an event like a terrorist attack, having an infinite population of similar attacks in the past, so that the event probability can be calculated is not feasible. In this case, we would need to assume a fictional population of non-existing past occurrences so that the event probability can be calculated.

2. Continuous Consequences: there are situations when a discrete failure event cannot be defined, for e.g. risk of incurring financial losses due to changes /volatility in foreign exchange or interest rates over a period of time. In this case, risk is quantified by measures such as Value at Risk $(V a R)$ or Conditional Value at Risk $(C V a R)$. Value at Risk is a statistical measure which denotes the amount of money a portfolio, investment strategy or a firm is expected to lose over a given period of time for a specified confidence interval. Conditional Value at Risk is an extension of the Value at Risk concept and gives the average loss beyond the Value at Risk Confidence level (Heckmann, et al., 2015).

\subsection{Supply Chain Risk}

The term "Supply Chain Risk" has diverse interpretations in supply chain risk management literature. The most commonly found definition is based on magnitude of potential losses incurred by the firms in the supply chain due to undesirable deviations from the expected supply chain performance measures or outcomes caused by triggering of disruptive events. The disruptive events are characterized by their probability of occurrence and the associated impact on the supply chain (Heckmann, et al., 2015) and (Ho, et al., 2015). According to Kajüter (as cited in Heckmann, et al., 2015), supply chain risks could be Cumulative, Additive, or Singular. Cumulative supply chain risks intesify as they propogate along the supply chain, additive risks have negative effects along the supply chain when they occur together, while singular risks are locally isolated risks which do not impact the rest of the supply chain.

(Norman \& Jansson, 2004), quantify risk as given in Eq. (1). The same formula is also typically used for quantifying supply chain risks as well. In order to avoid the issues related to calculation of probabilities of occurrence of disruptive events due to lack of sufficient historical data, (Norman \& Jansson, 2004) document the use of "Business Impact Value" (BIV) which is defined as a product of gross 
margin and "Business Recovery Time" (BRT) plus extra costs, to rank and prioritize risks. (Simchi-Levi, et al., 2015), evaluate the impact on a supply chain performance measure, of a disruptive event at a node in the supply chain (such as at a supplier facility or a distribution center) lasting for the duration of "Time to Recovery" (TTR). TTR is defined as the time taken by the node to resume full functionality post disruption and is increasingly being used to evaluate supply chain risks.

(Heckmann, et al., 2015), have also documented use by various researchers of other risk measures such as Variance or Standard Deviation, Value at Risk, or Conditional Value at Risk for quantifying supply chain risk.

\subsection{Supply Chain Risk Management (SCRM)}

The discipline of supply chain risk management evolved out of the need to ensure business continuity in the presence of supply chain risks. Since SCRM is a relatively new discipline, currently there is no consensus on the definition of SCRM (Sodhi, et al., 2012). SCRM is broadly defined in literature as a Collaborative endeavor between supply chain partners aimed at identifying and managing risks so as to reduce supply chain vulnerability to risks and ensure its profitability and continuity. Various researchers have proposed SCRM approaches including (Hallikas, et al., 2004), (Kleindorfer \& Saad, 2005), (Manuj \& Mentzer, 2008), (Zsidisin \& Ritchie, 2009) and (Tummala \& Schoenherr, 2011). According to (Tummala \& Schoenherr, 2011), SCRM process consists of the following steps:

1. Risk Identification - involves a comprehensive and structured identification of supply chain risks.

2. Risk Measurement-determination of the consequences of all identified supply chain risks along with magnitudes of their impact.

3. Risk Assessment - assessing likelihood of each risk factor.

4. Risk Evaluation - consists of two sub-steps of risk ranking and risk acceptance.

a) Risk ranking - involves determining risk exposure value of each risk factor based on consequence severity and probability of occurrence and grouping risks into classes based on risk exposure values

b) Risk Acceptance - after supply chain risks are grouped into classes they are further classified into unacceptable, tolerable or acceptable risks based on criteria defined by the organization.

5. Risk Mitigation and contingency plans -risk mitigation and contingency plans are developed taking into account resource constraints faced by the organization.

6. Risk Monitoring and Control -involves monitoring performance of risk response plans, taking corrective and preventive actions to account for deviations from desired SC performance, abnormal cases or SC disruptions.

(Zsidisin \& Ritchie, 2009), suggest that SCRM process also includes Organizational and Personal Learning including Knowledge Transfer as a step. This involves capturing risk management know how and lessons learnt by individuals and organizations in the supply chain and sharing them within the organization and with other supply chain partners.

\subsection{Classification of Supply Chain Risks}

Risk identification is an important first step in the SCRM process. Once the risks have been identified it is important to classify them into different categories to help risk managers understand the universe of risk categories as well as the events and conditions that drive them. This understanding will then facilitate selection and design of different risk mitigation strategies which are likely to be most effective (Chopra \& Sodhi, 2004). Classification of risks also helps in deciding which entity within the organization or the supply chain will be responsible for managing a particular risk category (Sodhi \& Tang, 2012).

The derived risk categories which result from the risk classification process are known as Risk Sources. According to (Jüttner, et al., 2003), Risk Sources are "the environmental, organizational or supply chain related variables which cannot be predicted with certainty and which impact on the supply chain outcome variables". Some researchers, for e.g. (Ho, et al., 2015), have used the term Risk Types instead of Risk Sources.

While each supply chain and organizations within the supply chain are unique in terms of the risks they face, it is important to have a universally accepted classification of supply chain risks in order to establish a common vocabulary for risk identification and assessment between organizations in a supply chain and to standardize risk mitigation strategies for known supply chain risks. One of the drawbacks of having such a universally accepted classification scheme could be that the user of the scheme gets stuck into a patterned way of thinking. However, benefit of having a well-defined starting point and rigor of a structured approach outweighs this drawback. Further, such a classification scheme could serve as a significant repository of knowledge within the discipline, for e.g. the insurance underwriting process uses a risk classification scheme which serves as the basis for insurance risk assessment and knowledge base for the underwriters (Asbjørnslett, 2009).

\section{RESEARCH METHODOLOGY}

For the purpose of this literature review, we analyzed articles on SCRM published in various journals following the methodology of a content analysis based literature review proposed by (Seuring \& Gold, 2012). The steps in our research methodology are summarized as follows:

1. Material Collection - The literature review is bounded to include articles per the following filtering criteria. Articles were analyzed and those not meeting the filtering criteria were excluded from the review.

a) The article must be a Peer reviewed journal article written in English and published in International Journals between 2003 and 2015.

b) The article should provide a new classification scheme for supply chain risks or define new supply chain risk sources.

For the time period between 2003 and 2013, all 224 articles reviewed by (Ho, et al., 2015) were considered for application of filtering criteria. These articles were a result of the search performed by the authors using the keywords "supply chain" and "risk". The databases used for the search by the authors included EBSCOhost, Emerald, IEEExplore, Ingenta, Metapress, ProQuest, ScienceDirect, Springer, Taylor 


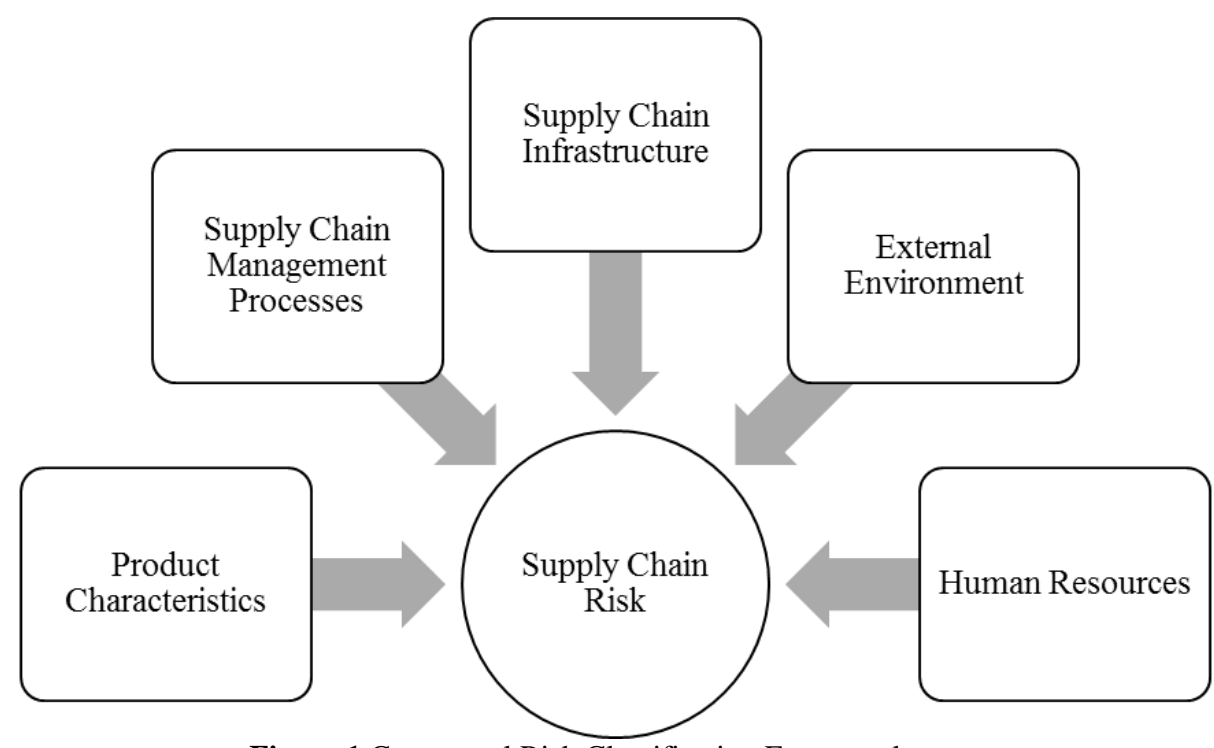

Figure 1 Conceptual Risk Classification Framework

and Francis, and WileyFirst. Application of Filtering Criteria resulted in short listing of 22 journal articles.

For the time period between 2014 and 2015, we conducted a search on Google Scholar search engine for articles containing the exact phrase, "Supply Chain" and atleast one of the words "risk" or "sources" anywhere in the article. This search returned 1260 articles sorted by date. Further analysis of these articles as per the filtering criteria resulted in short listing of articles by (Blos, et al., 2015) and (Ho, et al., 2015).

We also conducted a backward search by looking at the references list of shortlisted articles and a Forward search looking at articles which have cited the shortlisted articles to identify potential articles which could be added to our review. This process resulted in short listing of article by (Rangel, et al., 2014).

Thus, the material collection step resulted in 25 Journal articles which were then taken up for further review.

2. Descriptive Analysis - In this step, we analyzed the temporal distribution of the articles over the time period between 2003 and 2015. We also analyzed the distribution of the articles across the various journals and the aim /main topic of the article.

3. Category Selection- We decided to follow bottoms up approach of mapping the risks identified by the various researchers into a conceptual risk classification framework identified by authors, based on our synthesis of Supply Chain Risk Management Literature. The framework, as shown in Figure 1, is based on salient sources of risk for a product driven supply chain. These risk sources are -Product characteristics, Supply Chain Management Processes as documented in the SCOR model (Supply Chain Council, 2010), Supply Chain Infrastructure, External Environment, and Human Resources. Supply Chain Infrastructure is further split into dimensions of Manufacturing Facilities, Transportation, Information
Systems and Financial factors while Human Resource includes Organization as a risk source.

The articles were analyzed by mapping the various risks identified therein into the conceptual framework. This mapping revealed the risk sources addressed by the various risk classification schemes.

4. Material Evaluation -Based on the analysis of various risk classification schemes using the conceptual framework, we drew conclusions, identified research gaps and future research directions.

\section{RESULTS}

\subsection{Descriptive Analysis}

The temporal distribution of articles is shown in Figure 2. The distribution of articles across various journals and their main topics are listed in Table 1. It is seen that over the time period between 2003 and 2015, while there has been a sustained interest in Supply chain risk classification there is no large body of research devoted to the subject. The topic has either been a main research topic for the various researchers or has been addressed as a part of a different research goal.

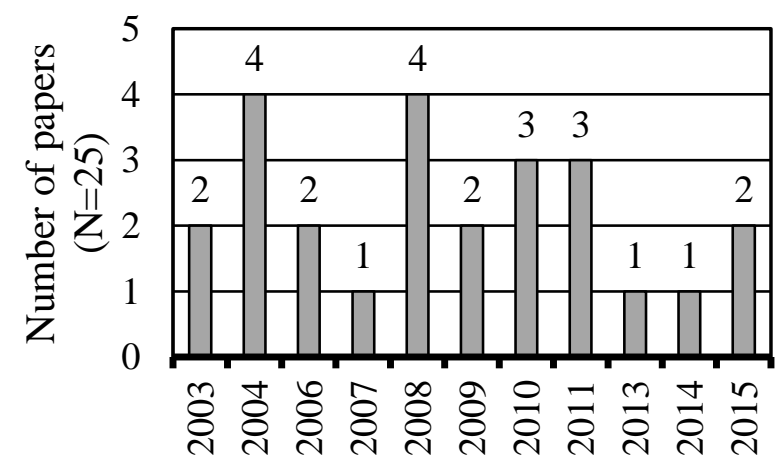

Figure 2 Allocation of Articles Across the Analyzed Period 20032015 
Table 1 Main Topics of Reviewed Articles and Their Journal Distribution

\begin{tabular}{|c|c|c|}
\hline Authors & Journal & Aim /Main Topic \\
\hline Harland, Brenchley, \& Walker, 2003 & JPSM & Definitions and classification of types of risks, risk management tool \\
\hline Jüttner, Peck, \& Christopher, 2003 & IJL & Identify agenda for future research in supply chain risk management \\
\hline Cavinato, 2004 & IJPDLM & Categorization of risks and uncertainties in a supply chain \\
\hline Chopra \& Sodhi, 2004 & MSMR & Supply chain risks and risk management strategies \\
\hline Christopher \& Peck, 2004 & IJLM & Identification and management of supply chain risk, supply chain resilience \\
\hline Hallikas et al., 2004 & IJPE & Risk management in supplier networks \\
\hline Wu, Blackhurst, \& Chidambaram, 2006 & $\mathrm{Cll}$ & $\begin{array}{l}\text { Integrated methodology to classify, manage and assess inbound supply } \\
\text { chain risk }\end{array}$ \\
\hline Tang C. S., 2006 & IJPE & Review of quantitative models for managing supply chain risks \\
\hline Bogataj \& Bogataj, 2007 & IJPE & Quantitative analysis of supply chain risk \\
\hline Manuj \& Mentzer, 2008 & IJPDLM & Supply chain risk management and risk management strategies \\
\hline Tang \& Tomlin, 2008 & IJPE & Flexible Strategies for reducing supply chain risks \\
\hline Wagner \& Bode, 2008 & $\mathrm{JBL}$ & Relationship between supply chain risk sources and firm performance \\
\hline Blackhurst, Scheibe, \& Johnson, 2008 & IJPDLM & Supplier risk assessment methodology for automotive manufacturer \\
\hline Rao \& Goldsby, 2009 & IJLM & Literature review of SCRM, typology of supply chain risks \\
\hline Trkman \& McCormack, 2009 & IJPE & $\begin{array}{l}\text { Identification and prediction of supply risk, assessment and classification of } \\
\text { suppliers }\end{array}$ \\
\hline Kumar, Tiwari, \& Babiceanu, 2010 & IJPR & Identification of supply chain risks, quantitative analysis of risks \\
\hline Olson \& Wu, 2010 & K & Review approaches to SCRM, discuss supply chain risks involving China \\
\hline Ravindran, Bilsel, \& Yang, 2010 & IJPR & $\begin{array}{l}\text { Development of multi-criteria supplier selection models incorporating supply } \\
\text { risk }\end{array}$ \\
\hline Lin \& Zhou, 2011 & IJPDLM & Impact of product design changes on supply chain risk \\
\hline Tang \& Musa, 2011 & IJPE & Review research developments in SCRM \\
\hline Tummala \& Schoenherr, 2011 & SCM & SCRM Approach \\
\hline Samvedi, Jain, \& Chan, 2013 & IJPR & $\begin{array}{l}\text { Quantitative Analysis of supply chain risks using fuzzy AHP and fuzzy } \\
\text { TOPSIS }\end{array}$ \\
\hline Rangel, Oliveira, \& Leite, 2014 & IJPR & Classification scheme for supply chain risks \\
\hline Blos, Hoeflich, Dias, \& Wee, 2015 & IJPR & Classification scheme for supply chain risks \\
\hline Ho, Yildiz, \& Talluri, 2015 & IJPR & Literature review of SCRM, Classification scheme for supply chain risks \\
\hline
\end{tabular}

Notes: Legend and journal count - Computers In Industry (CII = 1); International Journal of Logistics (IJL = 1); International Journal of Logistics Management (IJLM = 2); International Journal of Physical Distribution and Logistics Management (IJPDLM = 4); International Journal of Production Economics (IJPE = 6); International Journal of Production Research (IJPR = 6); Journal of Business Logistics (JBL = 1); Journal of Purchasing and Supply Management (JPSM = 1); Kybernetes (K=1); MIT Sloan Management Review (MSMR = 1); Supply Chain Management (SCM =1) 


\subsection{Category Selection}

The different supply chain risk classification schemes proposed by the various researchers and the various risk sources identified by them, over the time period between 2003 and 2015, have been documented in Table 2. The following conclusions can be drawn from the table:

1. There is a wide variety in the terminology used to identify the various risk sources

2. Some risk classification schemes are fairly explicit while others take a very generic /broad based approach

Table 3 gives an illustrative list of supply chain risks with their definitions, mapped to the conceptual research framework. The list has been compiled from the work of various researchers, most notably (Maruchek, et al., 2011), (Chopra \& Sodhi, 2004), (Olson \& Wu, 2010), (Blos, et al., 2015), (Tummala \& Schoenherr, 2011), (Rangel, et al., 2014), (Hallikas, et al., 2004), and (Tang \& Musa, 2011). The listing was also compared against (Alcantara \& Riglietti, 2015) to gauge alignment with practitioner perspectives.

The mapping of various supply chain risks identified by the researchers over the time period between 2003 and 2015 into the conceptual research framework in accordance with the risk listing and definitions in Table $\mathbf{3}$ is presented in Table 4. As can be seen from the frequency counts in the table, the different types of risk are fairly well represented in the work of various researchers with the notable exception of the following:

1. Risks associated with the product characteristics namely raw materials, product composition, packaging, labeling, and diversion in transit

2. Risks due to E-Commerce, information delays and data breach in Information Technology systems

3. Risks due to changes in interest rates, unexpected movement in market prices, contract terms, duration of contracts and asset impairment in Financial Factors

4. Risks associated with process instability, poor process yields, poor working conditions, and lack of maintenance in manufacturing facilities

5. Risks associated with supplier monopoly due to supplier intellectual property /patents in source process

6. Risks associated with legal implications of recycling, recycling and reprocessing in Return process and inventory holding due to inability to recycle /reprocess

7. Risks associated with improper capacity planning, lack of integration, shared responsibility and coordination in the Plan process

8. Risks associated with lack of business ethics, employee dissatisfaction, workplace rights, employee turnover and illness in Human Resources

9. Risks associated with Cultural differences between members of a supply chain and Sovereign Default in External Environment

Table 2 Supply Chain Risk Sources Identified by Researchers

Authors Risk Sources

Harland, Brenchley, \& Walker, 2003

Jüttner, Peck, \& Christopher, 2003

Cavinato, 2004

Chopra \& Sodhi, 2004

Christopher \& Peck, 2004

Hallikas et al., 2004

Tang C. S., 2006

Wu et al., 2006

Bogataj \& Bogataj, 2007

Blackhurst, Scheibe, \& Johnson, 2008

Manuj \& Mentzer, 2008
Strategic, operations, supply, customer, asset impairment, competitive, reputation,

financial, fiscal, regulatory, and legal risks

Environmental, Network, Organizational

Physical, Financial, Informational, Relational, Innovational

Disruptions, Delays, Systems, Forecast, Intellectual Property, Procurement, Receivables, Inventory, Capacity

Internal to the firm: process risk, control risk; External to the firm but internal to the supply chain network: Demand risk, supply risk; External to the network: Environmental risk

Demand, Customer Deliveries, Cost Management \& Pricing, Weakness in resources, development and flexibility

Operational risks: uncertain demand, uncertain supply yields, uncertain supply lead times and uncertain supply costs; Disruption Risks: earthquakes, floods, hurricanes, terrorist attacks, economics crises such as currency evaluation and strikes

Internal risks and external risks: controllable, partially controllable, uncontrollable Supply, Process (Production or Distribution), Demand, Control, Environmental Disruptions /Disasters, Logistics, Supplier Dependence, Quality, Information Systems, Forecast, Legal, Intellectual Property, Procurement, Receivables, Inventory, Capacity, Management, Security Risks

Supply, demand, operational, and other risks such as currency fluctuations, wage rate shifts, security 
Table 2 Supply Chain Risk Sources Identified by Researchers (Con't)

Authors Risk Sources

Tang \& Tomlin, 2008

Wagner \& Bode, 2008

Trkman \& McCormack, 2009

Rao \& Goldsby, 2009

Kumar, Tiwari, \& Babiceanu, 2010

Olson \& Wu, 2010

Ravindran, Bilsel, \& Yang, 2010

Lin \& Zhou, 2011

Tang \& Musa, 2011

Tummala \& Schoenherr, 2011

Samvedi, Jain, \& Chan, 2013

Rangel, Oliveira, \& Leite, 2014

Blos, Hoeflich, Dias, \& Wee, 2015

Ho, Yildiz, \& Talluri, 2015
Supply, Process, Demand, Intellectual Property, Behavioral, Political /Social risks

Demand, Supply, Regulatory, legal and bureaucratic, Infrastructure, Catastrophic

Endogenous risks: market turbulence, technology turbulence; Exogenous risks: discrete events, continuous risks

Environmental Factors, Organizational Factors, Industry Factors, Problem Specific

Factors, Decision Maker factors

Demand, production and distribution, supply and interaction risks Internal Risks: available capacity, internal operation, information system risks,

External risks: nature, political system, competitor and market risks

Value at Risk (VaR): Labor strike, terrorist attack, natural disaster,

Miss the Target (MtT): Late delivery, missing quality requirements

Internal risk, risk within the supply chain, risk in the external environment

Material flow risk, Financial flow risk, Information flow risk

Demand, delay, disruption, inventory, manufacturing (process) breakdown, physical plant

(capacity), supply (procurement), system, sovereign, transportation risks

Supply, Demand, Process, Environmental risks

Strategic, Inertia, Informational, Capacity, Demand, Supply, Financial, Relational,

Operational, Disruption, Customer, Legal, Environmental, Culture

Water, Raw Material, Ingredient, Packaging, Manufacturing Process, Infrastructure and natural hazards, Energy, Environmental, Worker Safety and health risks, People, skills and availability Risks, Information and systems risks, Route to market and in market risks, Legal, Legislative and regulatory risks, Workplace rights and social responsibility Natural Risks, Manmade Risks, Manufacturing Risks, Demand Risks, Supply Risks, Information Technology risks, Transportation risks, Financial systems risks

Table 3 Supply Chain Risk Sources and Risks

\begin{tabular}{lll}
\hline Risk Source & Risk & Risk Description \\
\hline Product Characteristics & Raw Materials & Nature and availability of Raw Materials \\
\hline & Product Composition & Changes in Product Composition during transit through the supply chain \\
\hline Suitability for End Use & Changes in suitability of a Product for its intended End Use which could be due \\
& to contamination or damage during transit through the supply chain \\
\hline Packaging & Product damage due to inadequate packaging during transportation or for sale \\
\hline Labeling & Risk to End Users of a Product due to its mislabeling \\
\hline Diversion & Product loss due to diversion during transit through the Supply Chain \\
\hline Intellectual Property & Product related IP lost due to lack of data security in the supply chain \\
\hline Design Changes & Frequent Product design changes \\
\hline Development Delay & Inordinate delays in Product Development, Innovation risk \\
\hline Product Quality & Unacceptable Product Quality \\
\hline Product Obsolescence & Product obsolescence and perishability \\
\hline Substitution Alternatives & Product substitution with its alternatives \\
\hline
\end{tabular}


Table 3 Supply Chain Risk Sources and Risks (Con't)

\begin{tabular}{|c|c|c|}
\hline Risk Source & Risk & Risk Description \\
\hline \multirow[t]{7}{*}{ Information Systems } & IT Infrastructure Failure & Failure of IT and /or Telecommunication Networks \\
\hline & System Integration & Incompatibility of IT Systems between organizations in the supply chain \\
\hline & Cyber Attack & Vulnerability of IT System to Cyber Attack due to for e.g. viruses /bugs /hackers \\
\hline & E-Commerce & Risks associated with e-Commerce implementation \\
\hline & Information delays & Delay in transmission of information across the supply chain \\
\hline & Information distortion & Information distortion across the supply chain \\
\hline & Data Breach & Data breach in information network \\
\hline \multirow[t]{5}{*}{ Transportation } & Transport Network & Disruption of Transport Network \\
\hline & Network Complexity & Complexity, length of transport network \\
\hline & Multimodal Transport & Product damage during product handling in multimodal transport \\
\hline & Transshipment & Product damage during handling in transshipment \\
\hline & Transport Delay & Risk to On-time /On-budget delivery due to delays in the transport network \\
\hline \multirow[t]{9}{*}{ Financial Factors } & Funding liquidity & Inability to obtain funding to meet obligations \\
\hline & Currency & Currency exchange rate fluctuations \\
\hline & Interest Rate & Interest rate fluctuations \\
\hline & Insolvency & Insolvency of supply chain partners \\
\hline & Market & Due to unexpected movement in market prices \\
\hline & Contracts & Implications of contract terms, short term v/s long term contract \\
\hline & Fiscal Risk & Due to changes in taxation \\
\hline & Asset Impairment Risk & $\begin{array}{l}\text { Due to for e.g. Physical damage to an asset, other reasons causing permanent } \\
\text { reduction in market value of the asset or reduction in asset utilization }\end{array}$ \\
\hline & Market Liquidity & Inability to sell assets when needed \\
\hline \multirow[t]{12}{*}{ Manufacturing Facilities } & Facility breakdown & Breakdown of machinery, equipment or production facilities \\
\hline & Worker Strikes & Lost production due to worker strikes /labor disputes \\
\hline & Inventory & Inventory holding costs \\
\hline & Capacity & Manufacturing capacity constraints \\
\hline & Cost & Increases in Labor and Production costs \\
\hline & Flexibility & Inability to service market demand due to lack of production flexibility \\
\hline & Process stability & Production breakdown due to manufacturing process instability \\
\hline & Yield & Production shortfall due to insufficient process yields \\
\hline & HSE Incident & Production disruption due to health, safety or environmental incidents \\
\hline & Working conditions & Reduction in worker productivity due to poor working conditions \\
\hline & Maintenance & Plant breakdowns due to poor or insufficient maintenance \\
\hline & Plant Obsolescence & $\begin{array}{l}\text { Production inefficiencies or shortfall due to obsolete production technology or } \\
\text { equipment }\end{array}$ \\
\hline
\end{tabular}


Table 3 Supply Chain Risk Sources and Risks (Con't)

\begin{tabular}{|c|c|c|}
\hline Risk Source & Risk & Risk Description \\
\hline \multirow[t]{12}{*}{ Source Process } & Single Sourcing & Supply disruption from a sole supplier \\
\hline & Sourcing Flexibility & $\begin{array}{l}\text { Cost of switching between suppliers, capacity and responsiveness of alternate } \\
\text { suppliers }\end{array}$ \\
\hline & Outsourcing & $\begin{array}{l}\text { Additional risks due to outsourcing /offshoring of supplies - supplier reliability, } \\
\text { transport risk, country risk, exchange rate risk etc. }\end{array}$ \\
\hline & Delivery & Supplier delivery failures \\
\hline & Relational & $\begin{array}{l}\text { Associated with lack of cooperation from a Supply Chain Partner or with his } \\
\text { opportunistic behavior }\end{array}$ \\
\hline & Quality & Supplier quality issues \\
\hline & Yield & Low process yields at supplier facility \\
\hline & Material Cost & Increase in material costs \\
\hline & Capacity & Supplier capacity constraints \\
\hline & Market Shortages & Limited qualified sources of supply \\
\hline & Intellectual Property & Supplier monopoly due to patents \\
\hline & Technology & Technological Obsolescence \\
\hline \multirow[t]{3}{*}{ Make Process } & Operational disruptions & $\begin{array}{l}\text { Disruptions due to Natural Disasters, breakdown of Manufacturing facilities, } \\
\text { Human Resources, Policies and Processes }\end{array}$ \\
\hline & Capacity & Production shortfall due to capacity constraints \\
\hline & Design Changes & $\begin{array}{l}\text { Inability to reconfigure manufacturing processes due to changes in product } \\
\text { /process design }\end{array}$ \\
\hline \multirow[t]{4}{*}{ Deliver Process } & Product Delivery & $\begin{array}{l}\text { Deficient product delivery according to criteria such as quantity, quality and } \\
\text { delivery time }\end{array}$ \\
\hline & Customer & Affects Likelihood of customer placing orders \\
\hline & Demand Volatility & Changes in demand due to seasonality and volatility due to factors such as \\
\hline & & Bullwhip effect or changes in customer preferences \\
\hline \multirow[t]{3}{*}{ Return Process } & Legal & Legal implications of Environmental impact due to disposal of returned products \\
\hline & Recycling /Reprocessing & $\begin{array}{l}\text { Loss incurred in recycling the product or in selling the product in secondary } \\
\text { market }\end{array}$ \\
\hline & Inventory & $\begin{array}{l}\text { Inventory holding costs due to inability to recycle, dispose or reprocess returned } \\
\text { products }\end{array}$ \\
\hline \multirow[t]{4}{*}{ Plan Process } & Strategic & Lack of strategic planning and failure to sense and respond to market changes \\
\hline & Forecasting & Excessive inventories or product shortages due to errors in forecasting \\
\hline & Integration & $\begin{array}{l}\text { Lack of integration, shared risk management, accountability or team work across } \\
\text { the supply chain }\end{array}$ \\
\hline & Capacity & Over capacity or underutilization of capacity due to poor capacity planning \\
\hline
\end{tabular}


Table 3 Supply Chain Risk Sources and Risks (Con't)

\begin{tabular}{|c|c|c|}
\hline Risk Source & Risk & Risk Description \\
\hline \multirow[t]{10}{*}{ Human Resources } & Lack of skills & Impact due to lack /loss of skilled employees \\
\hline & Business Ethics Incident & Impact due to violation of ethics codes of conduct such as due to violation of \\
\hline & & Human rights, corruption \\
\hline & Employee dissatisfaction & Operational risks such as low quality, schedule delays \\
\hline & Employee Accident & \\
\hline & /lnjury & Financial, legal and reputational implications \\
\hline & Workplace rights & Legal implications of violating employee workplace rights \\
\hline & Employee Illness & $\begin{array}{l}\text { Impact on supply chain due to illness in single employee or a group of } \\
\text { employees }\end{array}$ \\
\hline & Organization & Organization policies and processes, managerial risk taking, Reputation Risks \\
\hline & Employee Turnover & Turnover costs and possible impact on wages \\
\hline \multirow[t]{15}{*}{ External Environment } & Natural Disasters & Supply chain disruptions due to natural disasters \\
\hline & Security & Supply chain disruptions due to acts of war, pirate attacks, high way thefts \\
\hline & Terrorism & Supply chain disruptions due to Terrorism \\
\hline & Political Instability & Implications due to political instability \\
\hline & Legal & Cost impact of legal compliance or litigation \\
\hline & Government regulations & Cost impact of compliance with government regulations \\
\hline & Economic & Economic Instability in the country of operation, changes in CPI /GDP \\
\hline & Social Instability & Implications due to social unrest in region where supply chain operates \\
\hline & Cultural & Implications due to risks caused by cultural differences \\
\hline & Sovereign Default & $\begin{array}{l}\text { Financial implications of sovereign default in countries where supply chain } \\
\text { operates }\end{array}$ \\
\hline & Fire & Supply chain disruptions due to Fire \\
\hline & Diseases /Epidemics & Food supply chain disruptions due to animal disease \\
\hline & Market Characteristics & Implications of market size, market growth rate in relation to supplier capabilities \\
\hline & Competitive & Inability to differentiate products from competitor \\
\hline & Energy & Energy shortage, unreliable energy sources, cost of energy \\
\hline
\end{tabular}




\begin{tabular}{|c|c|c|c|c|c|c|c|c|c|c|c|c|c|c|c|c|c|c|c|c|c|c|c|c|c|c|}
\hline Risk Source & Risk & 1 & 2 & 3 & 4 & 5 & $\begin{array}{ll}6 & 7\end{array}$ & 8 & 9 & 10 & 11 & 12 & 13 & 14 & 15 & 16 & 17 & 18 & 19 & 20 & 21 & 22 & 23 & 24 & 25 & Count \\
\hline \multirow[t]{14}{*}{ Product Characteristics } & Raw Materials & & & & & & & & & & & & & & & & & & & & & & & $x$ & & 1 \\
\hline & Product Composition & & & & & & & & & & & & & & & & & & & & & & & $x$ & & 1 \\
\hline & Suitability for End & & & & & $x$ & & & $x$ & & & & & & & & & & & & & & & & & 2 \\
\hline & Use & & & & & & & & & & & & & & & & & & & & & & & & & \\
\hline & Packaging & & & & & & & & & & & & & & & & & & & & & & & $x$ & & 1 \\
\hline & Labeling & & & & & & & & & & & & & & & & & & & & & & & & & 0 \\
\hline & Diversion & & & & & & & & & & & & & & & & & & & & & & & & & 0 \\
\hline & Intellectual Property & & & & & & & & & $X$ & & $X$ & & & & & & & $X$ & $x$ & $x$ & & & & & 5 \\
\hline & Design Changes & & & & & & & $X$ & & & & & & & & & & & & & $x$ & & & & & 2 \\
\hline & Development Delay & & & $x$ & & & $x$ & & & & & & & & & & & & $X$ & & & & & & & 3 \\
\hline & Product Quality & & & & & & & & $X$ & $X$ & $X$ & & & & $X$ & $X$ & $X$ & & $x$ & & $x$ & $x$ & & & $X$ & 10 \\
\hline & $\begin{array}{l}\text { Product } \\
\text { Obsolescence }\end{array}$ & $x$ & & & $x$ & & & & & $x$ & & & & $x$ & $x$ & & $x$ & & & & $x$ & $x$ & $x$ & & & 9 \\
\hline & Substitution & & & & & & & & & $X$ & & & & & $X$ & & $X$ & & & & & & & & & 3 \\
\hline & Alternatives & & & & & & & & & & & & & & & & & & & & & & & & & \\
\hline \multirow[t]{7}{*}{ Information Systems } & $\begin{array}{l}\text { IT Infrastructure } \\
\text { Failure }\end{array}$ & & $X$ & $x$ & $X$ & & & & & $X$ & & & $X$ & & & & $X$ & & $X$ & $X$ & $x$ & & $x$ & $X$ & $X$ & 12 \\
\hline & System Integration & & & & $x$ & & & & & $X$ & & & $x$ & & & & $X$ & & $X$ & & $x$ & & $x$ & & & 7 \\
\hline & Cyber Attack & & & & & & & $x$ & & & & & $x$ & & & & $X$ & & $X$ & $x$ & & & & & & 5 \\
\hline & E-Commerce & & & & $X$ & & & & & & & & & & & & & & & & & & & & & 1 \\
\hline & Information delays & & & & & & & & & & & & & & & & & & $x$ & & & & & & & 1 \\
\hline & Information distortion & & $x$ & & $x$ & & & & & $X$ & & $x$ & $x$ & & & & $X$ & & $X$ & $x$ & $x$ & & $x$ & & & 10 \\
\hline & Data Breach & & & & & & & & & & & & & & & & & & & & & & & & & 0 \\
\hline \multirow[t]{5}{*}{ Transportation } & Transport Network & & & $x$ & & & & $x$ & & $X$ & & & $x$ & & & & & & $X$ & $x$ & $x$ & & & $x$ & $X$ & 9 \\
\hline & Network Complexity & & & & & & & & & $X$ & & & & & & & & & & & $x$ & & & & & 2 \\
\hline & Multimodal Transport & & & & $X$ & & & & & $X$ & & & & & & & & & & & $x$ & & & & & 3 \\
\hline & Transshipment & & & & & & & & & $X$ & & & & & & & & & & & $x$ & & & & & 2 \\
\hline & Transport Delay & & & $x$ & & & & & & & $x$ & & & & & & & & & & $x$ & & & & & 3 \\
\hline
\end{tabular}


Table 4 Mapping Supply Chain Risks to Conceptual Framework (Con't)

\begin{tabular}{|c|c|c|c|c|c|c|c|c|c|c|c|c|c|c|c|c|c|c|c|c|c|c|c|c|c|c|c|}
\hline Risk Source & Risk & 1 & 2 & 3 & 4 & 5 & 6 & 7 & 8 & 9 & 10 & 11 & 12 & 13 & 14 & 15 & 16 & 17 & 18 & 19 & 20 & 21 & 22 & 23 & 24 & 25 & Count \\
\hline \multirow[t]{9}{*}{ Financial Factors } & Funding liquidity & & & $X$ & & & & & $X$ & & & & & & & $\mathrm{X}$ & & $X$ & & & $\mathrm{X}$ & & & $x$ & & $X$ & 7 \\
\hline & Currency & & & & $X$ & & & $X$ & & & $X$ & $x$ & & & & & & $X$ & & & $X$ & $x$ & & $x$ & & & 8 \\
\hline & Interest Rate & & & & & & & & & & & & & & $x$ & & & & & & & & & & & & 1 \\
\hline & Insolvency & $x$ & & $X$ & $X$ & & & & & & $X$ & & & $x$ & & $x$ & & $x$ & & & $x$ & $x$ & $x$ & $x$ & & & 11 \\
\hline & Market & & & & & & & & & & & & & & & & & & & & & & & & $x$ & & 1 \\
\hline & Contracts & & & & $X$ & & & & & & & & & & & & & & & & & & & & & & 1 \\
\hline & Fiscal Risk & $X$ & & & & & & & & & & & & & & & & & & & & & & $x$ & & & 2 \\
\hline & Asset Impairment & $X$ & & & & & & & & & & & & & & & & & & & & & & & & & 1 \\
\hline & Market Liquidity & & & & & & & & & & & & & & & & & $x$ & & & $x$ & & & & & & 2 \\
\hline \multirow[t]{12}{*}{ Manufacturing Facilities } & Facility breakdown & $x$ & $x$ & & & & & & & & & $x$ & & & & & $X$ & & & & & & & $x$ & & & 5 \\
\hline & Worker Strikes & & $x$ & & $X$ & & & $x$ & $X$ & & $X$ & & & $x$ & $x$ & $X$ & & $x$ & $x$ & $x$ & & $x$ & $x$ & $x$ & & & 14 \\
\hline & Inventory & & & $X$ & $X$ & & & & $x$ & & $X$ & $x$ & & & & & & $X$ & & & $X$ & $x$ & & $x$ & & & 9 \\
\hline & Capacity & & & & $X$ & & & & $x$ & & $X$ & & & & & & & $X$ & & & & $x$ & & $x$ & & & 6 \\
\hline & Cost & & & & & & $x$ & & $X$ & & & & & & & & & & & $x$ & $X$ & $x$ & & & & & 5 \\
\hline & Flexibility & & $X$ & & $X$ & & $X$ & & $X$ & & $X$ & & & & & & & $X$ & & & & $x$ & & $x$ & & & 8 \\
\hline & Process stability & & & & & & & & & & & & & & & & & & & & & & & & & & 0 \\
\hline & Yield & & & & & & & & & & & & & & & & & & & & & $X$ & & & & & 1 \\
\hline & HSE Incident & & & & & $x$ & & & $X$ & & & & & $x$ & & & & & & & $X$ & & & $x$ & $x$ & & 6 \\
\hline & Working conditions & & & & & & & & & & & & & & & & & & & & & & & & & & 0 \\
\hline & Maintenance & & & & & & & & & & & & & & & & & & & & & & & & & & 0 \\
\hline & Plant Obsolescence & & & & & & & & & & & & & & $X$ & & & $x$ & & & & & $x$ & & & & 3 \\
\hline \multirow[t]{7}{*}{ Source Process } & Single Sourcing & & & & $X$ & & & & & & $x$ & & & & & & & & & & $x$ & $x$ & & $x$ & & & 5 \\
\hline & Sourcing Flexibility & & $x$ & & $X$ & & $X$ & & $X$ & & $X$ & & & & & & & $x$ & & & $X$ & $X$ & & $X$ & & & 9 \\
\hline & Outsourcing & & $x$ & & $X$ & & & & & & & & & & & & & & & & $x$ & & $x$ & $x$ & & & 5 \\
\hline & Delivery & $X$ & & & $X$ & $X$ & $X$ & $X$ & $X$ & $X$ & $X$ & $X$ & & $x$ & & $X$ & $X$ & $x$ & $X$ & $X$ & & $x$ & & $X$ & & $X$ & 18 \\
\hline & Relational & & & $X$ & & & & & & & & $X$ & $X$ & $X$ & & & & & & & $X$ & & & $x$ & & & 6 \\
\hline & Quality & & & & $X$ & & & & $X$ & $X$ & & $x$ & & $x$ & & $X$ & & $x$ & $X$ & $x$ & $x$ & $x$ & $X$ & $X$ & & & 13 \\
\hline & Yield & & & & $X$ & & & $X$ & & & & & & & & & & & & & & $x$ & & & & & 3 \\
\hline
\end{tabular}


Table 4 Mapping Supply Chain Risks to Conceptual Framework (Con't)

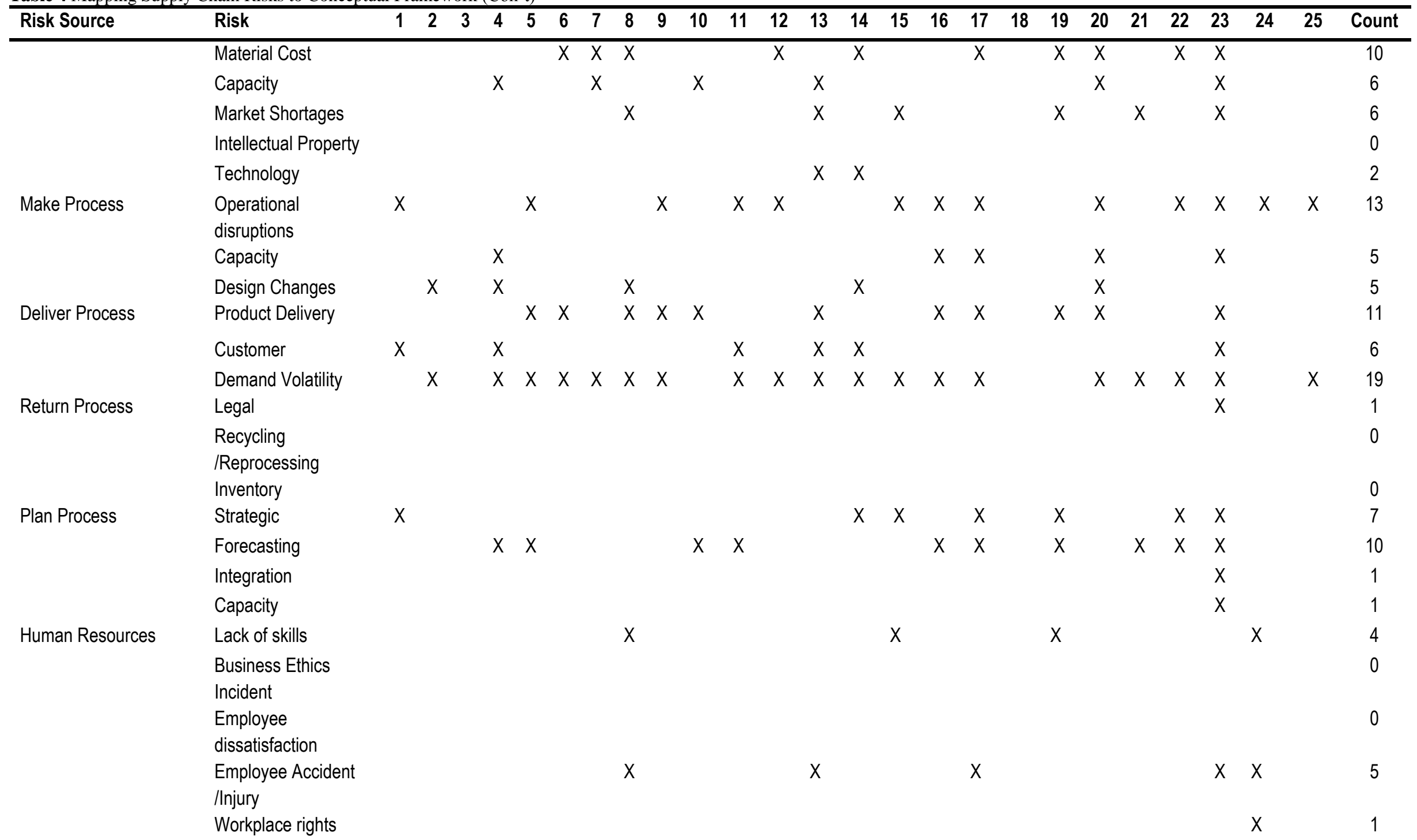


Hudnurkar et al.: Supply Chain Risk Classification Schemes: A Literature Review Operations and Supply Chain Management 10(4) pp. 182 - 199 @ 2017

Table 4 Mapping Supply Chain Risks to Conceptual Framework (Con't)

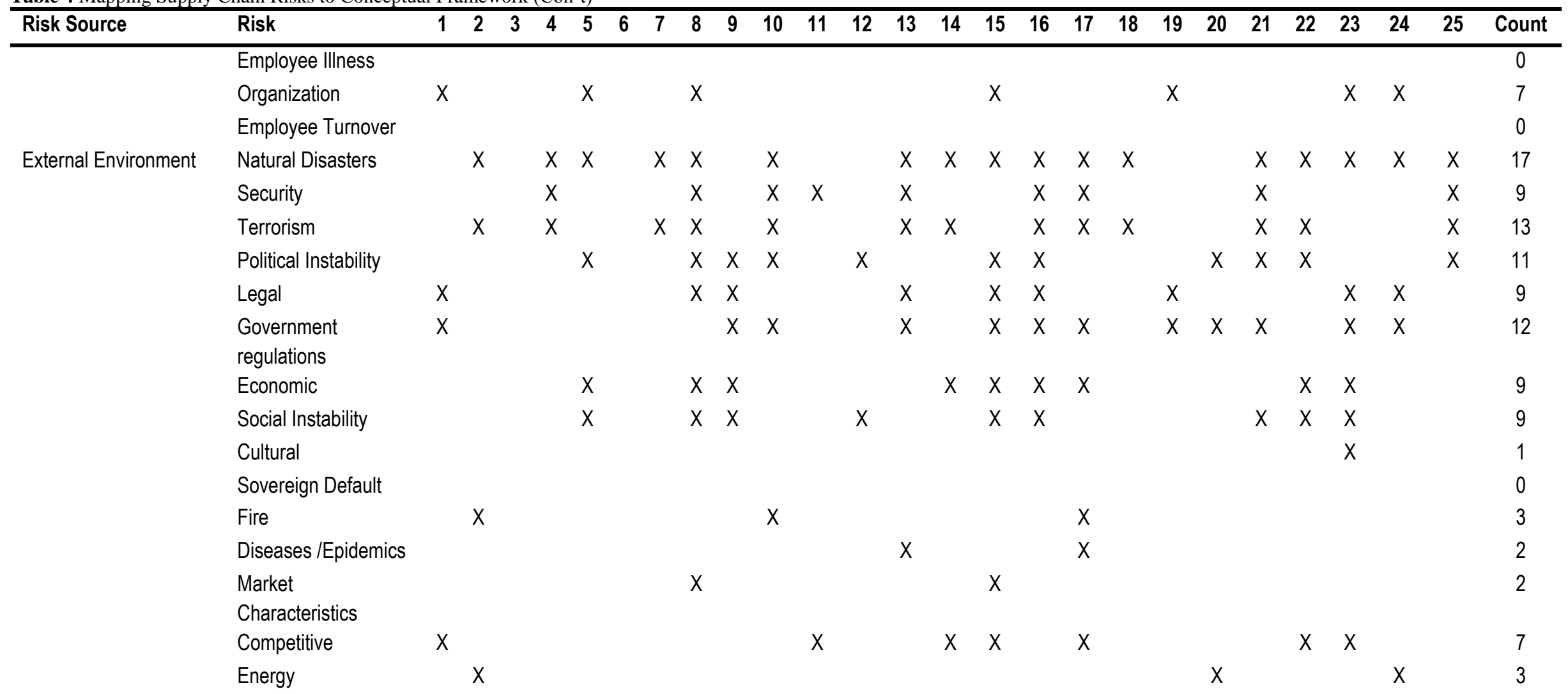

Notes: 1 - (Harland, et al., 2003); 2 - (Jüttner, et al., 2003); 3 - (Cavinato, 2004); 4 - (Chopra \& Sodhi, 2004); 5 - (Christopher \& Peck, 2004$) ; 6$ - (Hallikas, et al., 2004); 7 - (Tang, 2006); 8 (Wu, et al., 2006); 9 - (Bogataj \& Bogataj, 2007); 10 - (Blackhurst, et al., 2008); 11 - (Manuj \& Mentzer, 2008); 12 - (Tang \& Tomlin, 2008$) ; 13$ - (Wagner \& Bode, 2008); 14 - (Trkman \& McCormack, 2009); 15 - (Rao \& Goldsby, 2009); 16 - (Kumar, et al., 2010); 17 - (Olson \& Wu, 2010); 18 - (Ravindran, et al., 2010$) ; 19$ - (Lin \& Zhou, 2011 ); 20 - (Tang \& Musa, 2011 ); 21 (Tummala \& Schoenherr, 2011); 22 - (Samvedi, et al., 2013); 23 - (Rangel, et al., 2014); 24 - (Blos, et al., 2015); 25 - (Ho, et al., 2015) 


\section{DISCUSSION}

From the results, it is seen that while several supply chain risk classification schemes have comprehensively covered the various types of supply chain risks, there is a general lack of consensus between the various researchers regarding a universally accepted supply chain risk classification scheme. Of the papers reviewed, only 3 papers by (Rangel, et al., 2014), (Blos, et al., 2015) and (Ho, et al., 2015) have focused on supply chain risk classification as one of the primary subject of their research. Remaining 22 papers have classified supply chain risks as a part of a different research goal. This indicates that while there is awareness about classifying supply chain risks, there does not seem to be so much awareness about arriving at a universally acceptable risk classification scheme.

An analysis of the various supply chain risk classification schemes reveals that supply chain risks primarily arise due to internal environment within a supply chain i.e. SCM processes and supply chain infrastructure, interaction between a supply chain and the external environment in which it operates, characteristics of the product being handled by the supply chain, organizations and human resources which form and operate the supply chain.

(Rangel, et al., 2014) have mapped the various SC risks to respective SCM processes while (Blos, et al., 2015) have used ISO 31000 (ISO, 2009), ISO /IEC 27036-3 (ISO, 2013) and ISO 28000 (ISO, 2005) standards as a basis of SC risk classification. They have identified 14 different categories of risks as listed in Table 2. (Ho, et al., 2015) have classified the SC risks into Macro and Micro risks where Macro risks pertain to Natural and Man-made risks which are external to the supply chain while Micro risks arise out of internal operations of the supply chain such as Manufacturing Risks, Demand Risks, Supply Risks, Information Technology risks, Transportation risks, Financial systems risks.

In comparison, the risk classification framework being proposed by the authors,not only incorporates SC Internal Environment which includes - SCM Processes and Supply Chain Infrastructure (Manufacturing Facilities, Transportation, Information Systems and Financial factors) and SC External Environment but also extends the framework to include dimensions of Product characteristics, Organizations and Human Resources. This framework enables comprehensive classification of different supply chain risks identified by the researchers and helps identify supply chain risks where further research is necessary.

\section{CONCLUSION}

In this paper, we have reviewed journal articles from the time period between 2003 and 2015 related to supply chain risk classification schemes and risk sources. Using a conceptual risk classification framework developed by us, we have provided a comprehensive listing of supply chain risks identified in literature along with their definitions.

It is clear from the results of our analysis that certain risks associated with Product Characteristics for e.g. Risk to end users of a product due to mislabeling during transit, loss of product due to diversion in transit, have not been studied /Identified by the researchers so far. Since, there have been numerous safety related incidents associated with Food and
Pharmaceutical products as documented by (Maruchek, et al., 2011); there is a need for further research in this area. The same is true for some risks originating from information systems, financial factors, manufacturing facilities, source process, return process, plan process, human resources and external environment risk sources in the conceptual framework.

With the advent of ISO 31000 standard (ISO, 2009) which provides general principles, definitions and guidance on risk management, ISO 28000 standard (ISO, 2005) which deals with supply chain security and ISO/IEC 27036-3:2013 standard (ISO, 2013) which deals with Information security requirements for a supply chain, it is argued by (Blos, et al., 2015) that these standards provide a basis for a comprehensive, universally acceptable supply chain risk classification scheme. However, according to researchers like (Kaplan \& Mikes, 2015); risk management is still an emerging, largely unproven discipline and has not yet reached a maturity level where it can be standardized. There is clearly a need for more research across industry sectors and supply chain types to achieve standardization of supply chain risk classification scheme. This will enable standardization of risk management approaches for risks which are known and well documented in industry.

The main contribution of this paper is a new, comprehensive conceptual risk classification framework developed based on the review and analysis of extant literature. The framework which is comprised of dimensions of - Product characteristics, SCM Processes, SC Infrastructure, External Environment, and Human resources, effectively addresses the diverse risks faced by a typical product supply chain. It is hoped that this framework will provide a good starting point for a universal supply chain risk classification scheme. The review takes into account the current thinking on concept of risk and supply chain risks and also identifies directions for future research.

At the same time, this paper is not without its limitations. Our review has focused only on journal articles with the exclusion of dissertations, books, conference papers, notes etc. Used in conjunction with the research gaps and further research opportunities identified by us, this comprehensive documentation will serve as a solid foundation for further research into supply chain risks and risk classification schemes and will also be useful for other researchers in this area.

\section{REFERENCES}

Alcantara, P. \& Riglietti, G. (2015),Supply Chain Resilience Report,Business Continuity Institute, Caversham UK.

Asbjørnslett, B. E. (2009), Assessing the Vulnerability of Supply Chains,Supply Chain Risk: A Handbook of Assessment, Management, and Performance.Springer, New York, pp. 1533.

Aven, T. (2008),Risk Analysis: Assessing Uncertainties beyond Expected Values and Probabilities,John Wiley \& Sons Ltd., Chichester(West Sussex).

Aven, T. (2012), The risk concept-historical and recent development trends, Reliability Engineering \& System Safety, 99 , pp. 33-44.

BBC News (2012),Hard drive maker Western Digital profits fall $36 \%$ - BBC News. [Online] Available at: http://www.bbc.com/news/business-16691839 [Accessed 2015].

Blackhurst, J., Scheibe, K. \& Johnson, D. (2008), Supplier risk 
assessment and monitoring for automotive industry,International Journal of Physical Distribution \& Logistics Management, 38, pp. 143-165.

Blos, M. F., Hoeflich, S. L., Dias, E. M. \& Wee, H.-M. (2015), A note on supply chain risk classification: discussion and proposal,International Journal of Production Research, pp. $1-2$.

Bogataj, D. \& Bogataj, M. (2007), Measuring the supply chain risk and vulnerability in frequency space,International Journal of Production Economics, 108, pp. 291-301.

Cavinato, J. L. (2004), Supply chain logistics risks: From the back room to the board room, International Journal of Physical Distribution \& Logistics Management, 34(5), pp. 383-387.

Chopra, S. \& Sodhi, M. S. (2004), Managing Risk to Avoid SupplyChain Breakdown,MIT Sloan Management Review, 46(1), pp. 53-61.

Christopher, M. \& Peck, H. (2004), Building the Resilient Supply Chain,International Journal of Logistics Management, 15(2), pp. 1-13.

Christopher, M. \& Peck, H. (2004), Building the Resilient Supply Chain,International Journal of Logistics Management, 15(2), pp. 1-13.

Ghadge, A., Dani, S. \& Kalawsky, R. S. (2012), Supply Chain Risk Management: Present and Future Scope,International Journal of Logistics Management, 23(3), pp. 313-339.

Hallikas, J., Karvonen, I., Pulkikinen, U., Virolainen, V.M., \& Tuominen, M. (2004), Risk management processes in supplier networks, International Journal of Production Economics, 90(1), pp. 47-58.

Haraguchi, M. \& Lall, U. (2013),Flood Risks and Impacts - Future Research Questions and Implication to Private Investment Decision-Making for Supply Chain Networks, The United Nations Office for Disaster Risk Reduction.

Harland, C., Brenchley, R. \& Walker, H. (2003), Risk in supply networks,Journal of Purchasing \& Supply Management, 9, pp. 51-62.

Heckmann, I., Comes, T. \& Nickel, S. (2015), A Critical Review on Supply Chain Risk - Definition, Measure and Modeling,Omega, 52, pp. 119-132.

Ho, W., Yildiz, H. \& Talluri, S. (2015), Supply Chain Risk Management: A Literature Review,International Journal of Production Research.

ISO (2005),ISO/PAS 28000:2005, Specification for Security Management Systems for the Supply Chain,International Organization for Standardization, Geneva.

ISO (2009),ISO 31000:2009, Risk management - Principles and guidelines,International Organization for Standardization, Geneva.

ISO (2013),ISO/IEC 27036-3:2013, Information technology -Security techniques -- Information security for supplier relationships -- Part 3, International Organization for Standardization, Geneva.

Jüttner, U., Peck, H. \& Christopher, M. (2003), Supply Chain Management: Outlining an agenda for future research,International Journal of Logistics: Research \& Applications, 6(4), pp. 197-210.

Kaplan, R. S. \& Mikes, A. (2015), When One Size Doesn't Fit All: Evolving Directions in the Research and Practice of Enterprise Risk Management,Journal of Applied Corporate Finance, 27(1), pp. 27-30.

Kleindorfer, P. R. \& Saad, G. H. (2005), Managing Disruption Risks in Supply Chains,Production and Operations Management, 14(1), pp. 53-68.

Kumar, S. K., Tiwari, M. K. \& Babiceanu, R. F. (2010), Minimisation of supply chain cost with embedded risk using computational intelligence approaches,International Journal of Production Research, 48(13), pp. 3717-3739.

Lin, Y. \& Zhou, L. (2011), The impacts of product design changes on supply chain risk: a case study,International Journal of Physical Distribution \& Logistics Management, 41(2), pp.
162-186

Manuj, I. \& Mentzer, J. T. (2008), Global supply chain risk management strategies,International Journal of Physical Distribution \& Logistics Management, 38(3), pp. 192-223.

Maruchek, A., Greis, N., Mena, C. \& Cai, L. (2011), Product safety and security in the global supply chain: Issues, challenges and research opportunities,Journal of Operations Management, 29 , pp. 707-720.

Melynk, S. A., Davis, E. W., Spekman, R. E. \& Sandor, J. (2010), Outcome-Driven Supply Chains,MIT Sloan Management Review, 51(2), pp. 33-38.

Musa, N. S. (2012),Supply Chain Risk Management: Identification, Evaluation and Mitigation Techniques,Linköping University, Linköping.

Norman, A. \& Jansson, U. (2004), Ericsson's proactive supply chain risk management approach after a serious sub-supplier accident,International Journal of Physical Distribution \& Logistics Management, 34(5), pp. 434-456.

Olson, D. L. \& Wu, D. D. (2010), A review of enterprise risk management in supply chain,Kybernetes, 39(5), pp. 694-706.

Oxford Dictionaries (2015), risk. [Online] Available at:

http://www.oxforddictionaries.com/definition/english/risk [Accessed 21112015$].$

Pettit, T. J. (2008),Supply chain resilience: Development of a conceptual framework, an assessment tool and an implementation process, The Ohio State University, Columbus.

Rangel, D. A., Oliveira, T. K. d. \& Leite, M. S. A. (2014), Supply chain risk classification: discussion and proposal,International Journal of Production Research.

Rao, S. \& Goldsby, T. J. (2009), Supply chain risks: a review and typology,The International Journal of Logistics Management, 20(1), pp. 97-123.

Ravindran, A., Bilsel, R. W. V. \& Yang, T. (2010), Risk adjusted multicriteria supplier selection models with applications,International Journal of Production Research, 48, pp. 405-424.

Renn, O. (2008), A guide to Interdisciplinary Risk Research, In: Risk Governance: Coping with Uncertainty in a Complex World.Earthscan, London, pp. 1-12.

Samvedi, A., Jain, V. \& Chan, F. T. S. (2013), Quantifying risks in a supply chain through integration of fuzzy AHP and fuzzy TOPSIS,International Journal of Production Research, 51(8), pp. 2433-2442.

Seuring, S. \& Gold, S. (2012), Conducting content-analysis based literature reviews in supply chain management,Supply Chain Management: An International Journal, 17(5), pp. 544-555.

Simchi-Levi, D., Schmidt, W., Wei, Y., Yun Zhang, P., Combs, K., Ge, Y., Gusikhin, O., Sanders, M., Zhang, D. (2015), Identifying Risks and Mitigating Disruptions in the Automotive Supply Chain,Interfaces, 45(5), pp. 375-390.

Sodhi, M. S., Son, B.-G. \& Tang, C. S. (2012), Researchers' Perspectives on Supply Chain Risk Management,Production and Operations Management, 21(1), pp. 1-13.

Sodhi, M. S. \& Tang, C. S. (2012), Risk Identification, In: Managing Supply Chain Risk, Springer, New York, pp. 13-32.

Sodhi, M. S. \& Tang, C. S. (2012), Supply Chain Risk Management, In: Managing Supply Chain Risk.Springer, New York, pp. 3-11.

Supply Chain Council (2010),Supply Chain Operations Reference Model, Version 10.0, Supply Chain Council.

Sürie, C. \& Wagner, M. (2005), Supply Chain Analysis, In: C. Kilger \& H. Stadtler, eds. Supply Chain Management and Advanced Planning. 3 ed. Springer, Berlin, pp. 37-64.

Tang, C. S. (2006), Perspectives in supply chain risk management,International Journal of Production Economics, 103, pp. 451-488.

Tang, C. \& Tomlin, B. (2008), The Power of Flexibility for Mitigating Supply Chain Risks,International Journal of 
Production Economics, 116, pp. 12-27.

Tang, O. \& Musa, S. N. (2011), Identifying risk issues and research advancements in supply chain risk management,International Journal of Production Economics, 133, pp. 25-34.

Trkman, P. \& McCormack, K. (2009), Supply chain risk in turbulent environments - a conceptual model for managing supply chain network risk,International Journal of Production Economics, 119(2), pp. 247-258.

Tummala, R. \& Schoenherr, T. (2011), Assessing and managing risks using the Supply Chain Risk Management Process (SCRMP),Supply Chain Management: An International Journal, 16(6), pp. 474-483.
Wagner, S. M. \& Bode, C. (2008), An empirical examination of supply chain performance along several dimensions of risk,Journal of Business Logistics, 29(1), pp. 307-325.

Wu, T., Blackhurst, J. \& Chidambaram, V. (2006), A model for inbound supply risk analysis, Computers in Industry, 57, pp. 350-365.

Zsidisin, G. A. \& Ritchie, B. (2009), Supply Chain Risk Management - Developments, Issues and Challenges, In: G. A. Zsidisin \& B. Ritchie, eds. Supply Chain Risk: A Handbook of Assessment, Management, and Performance.Springer, New York, pp. 1-12.

Manoj Hudnurkar is a Professor and Head of Department in Operations Management and IT at Symbiosis Center for Management and Human Resource Development (SCMHRD), Symbiosis International University, Pune, India. Previously, he worked in Industry as Project Manager and has handled various projects. Manoj has published various papers in international journals of repute on collaborative supply chain management, supplier classification and supplier performance management. He also has experience in consulting projects and corporate trainings.

Sujeet Deshpande holds an MBA from Symbiosis Center for Management and Human Resource Development, Symbiosis International University, Pune, India. He has over 20 years of work experience in Systems Engineering and Project Management. His areas of research interest include Operations Management, Supply Chain Management and Business Strategy.

Urvashi Rathod is a Professor at Symbiosis International University (SIU), Pune, India; presently heading Symbiosis Centre for Research and Innovation (SCRI). She did Ph.D. from Birla Institute of Technology and Science, Pilani, India. She has been an entrepreneur for 8 years and later, after joining academics, she has been associated with IIM Indore, ICFAI Business School, International Institute of Information Technology and SIU. She teaches courses related to Information Technology and its application in business and society. Her research interest includes supply chains and information technology, software design and development and digital transformation. Her research work has been published in the journals of high repute. She is on Editorial Boards and Program Committees and a regular reviewer of research works.

Suresh K. Jakhar is working as an Assistant Professor in the Operations Management group at Indian Institute of Management (IIM) Lucknow, India. Prior to joining IIM Lucknow, he has worked at IIM Rohtak and SCMHRD, Pune. He has completed his M.Tech. from Indian Institute of Technology (IIT) Delhi and Ph.D. from IIT Roorkee. His research interests lie in the fields of Sustainable Operations, Supply Chain Management, Operations Research, Fuzzy Optimization and Game Theory. He has published in various journals such as Journal of Cleaner Production, Production Planning and Control, International Journal of Productivity and Performance Management, and Sustainable Development. 